\title{
Passive Transfer by Cells of Type II Collagen-Induced Arthritis in Rats
}

\author{
David E. Trentham, Roselynn A. Dynesius, and John R. David, Department \\ of Medicine, Harvard Medical School and Robert B. Brigham Hospital, Boston, \\ Massachusetts 02115
}

\begin{abstract}
A в S T R A C T To investigate the role of immunologic hypersensitivity to collagen in the causation of type II collagen-induced arthritis in rats, passive transfer experiments were performed. Wistar/Lewis rats used in these experiments were demonstrated to be histocompatible by prolonged skin graft survival and mixed lymphocyte cultures. Popliteal lymph node weight assays excluded a potential for graft-vs.-host reactivity in this strain. 9 of 32 naive rats developed arthritis after intravenous receipt of pooled spleen and lymph node cells from donors that had been injected intradermally with type II collagen emulsified in incomplete Freund's adjuvant. This passively transferred synovitis was evident clinically as well as histologically. In control cell transfer experiments involving a total of 97 recipients, transfer of arthritis was shown to require viable cells sensitized to type II collagen. These controls included 17 rats receiving cells from unimmunized donors, 20 recipients of cells from donors injected with incomplete Freund's adjuvant alone, and 24 recipients of cells from rats injected with type I collagen in adjuvant. Deliberate addition of solubilized type II collagen to unsensitized cells at the time of transfer or injection of heat-killed sensitized cells also did not cause arthritis in a total of 36 recipients. These latter two control groups indicate that disease transfer was not the result of antigen carry-over. Intravenous injection of sera from arthritic donors was incapable of passively transferring clinical or histologic synovitis in 30 recipients. Thus, these studies directly implicate immunologic sensitivity to the cartilage type of collagen in the etiology of this autoimmune disease.
\end{abstract}

\section{INTRODUCTION}

Type II collagen-induced arthritis is a recently described $(1,2)$ experimental model of autoimmunity in

\footnotetext{
A preliminary account of part of this work was presented at the Annual Meeting of the Federation of American Societies for Experimental Biology, 1-8 April 1977, Chicago, Ill.

Received for publication 11 November 1977 and in revised form 14 April 1978.
}

rats, produced by intradermal injection of a distinct type of collagen found in cartilage (type II collagen). Many features of this model, such as its proliferative synovitis, closely resemble rheumatoid arthritis $(1,2)$. The arthritis exhibits a specificity for native type II collagen, as immunization with type I and III collagens prepared from skin or the denatured $\alpha$-chains comprising type II do not cause disease. Moreover, type II collagens extracted from human, chick, or rat cartilage are all arthritogenic (1). Previous animal models of autoimmunity to a tissue component require use of adjuvant oil containing bacterial preparations to regularly induce disease (3). In contrast, the incidence and severity of arthritis (1) or magnitude of humoral or cellular sensitivity to type II collagen (2) in this disease is the same whether complete Freund's adjuvant (CFA) ${ }^{1}$ or incomplete Freund's adjuvant (ICFA; Difco Laboratories, Detroit, Mich.) is used. This property, i.e., the ability of heterologous or homologous type II collagen emulsified in ICFA to induce arthritis in $\cong 40 \%$ of several strains of rats, demonstrates the uniqueness of this protein in evoking an autoimmune response. It also indicates that this collagen-induced arthritis is distinct from the previously described adjuvant disease in the rat, which is induced by intradermal injection of CFA (1).

That immunologic mechanisms might be involved in the causation of type II collagen-induced arthritis was initially suggested by the dense infiltration of the synovium of arthritic joints by mononuclear cells (1). Also consistent with this hypothesis was the finding that the magnitude of both humoral and cellular sensitivity to type II collagen correlated with the occurrence of arthritis in rats injected intradermally with this protein (2). Passive transfer of type II collageninduced arthritis with cells, described in this paper,

\footnotetext{
${ }^{1}$ Abbreviations used in this paper: CFA, complete Freund's adjuvant; GVH, graft-vs.-host; $\left[{ }^{3} \mathrm{H}\right] \mathrm{TdR}$, tritiated thymidine; HBSS, Hanks' balanced salt solution; ICFA, incomplete Freund's adjuvant; MLC, mixed lymphocyte culture; W/L, Wistar/Lewis.
} 
directly implicates immunologic hypersensitivity to the cartilage type of collagen in the pathogenesis of this disease.

\section{METHODS}

Rats. Highly inbred female Wistar/Lewis (W/L) rats (Charles River Breeding Laboratories, Wilmington, Mass., and Microbiological Associates, Walkersville, Md.) weighing 125$175 \mathrm{~g}$ were used in all transfer experiments. Outbred female Wistar rats (Charles River Breeding Laboratories) of the same weight were used to obtain stimulator cells as a control for mixed lymphocyte culture (MLC) assays. Ear markings insured correct identification of all rats.

Histocompatibility evaluation. Histocompatibility of the W/L strain was tested by duration of survival of full thickness skin grafts (4) and MLC (5). To perform the MLC, blood was obtained by cardiac puncture from $\mathrm{W} / \mathrm{L}$ or Wistar rats, and mononuclear cells were isolated and cultured by a microtechnique we have previously described (2). After 5 days of culture, the mean counts per minute $\pm S E M$ tritiated thymidine $\left(\left[{ }^{3} \mathrm{H}\right] \mathrm{TdR}\right)$ incorporated by quadruplicate cultures of $2 \times 10^{5}$ cells from $1 \mathrm{~W} / \mathrm{L}$ rat were compared to the mean incorporation by quadruplicate cultures containing $1 \times 10^{5}$ cells from the first W/L rat mixed with $1 \times 10^{5}$ cells from a second W/L rat (two-way MLC). As a control, $\left[{ }^{3} \mathrm{H}\right] \mathrm{TdR}$ incorporation was measured in quadruplicate cultures of $1 \times 10^{5}$ cells from each $\mathrm{W} / \mathrm{L}$ rat mixed with $1 \times 10^{5}$ mitomycin-treated stimulator cells from a Wistar rat (one-way MLC). To further assess culture conditions, cells from each $\mathrm{W} / \mathrm{L}$ rat were also exposed to phytohemagglutinin (Difco Laboratories, Detroit, Mich.), recognizing that the mitogen responses were postmaximal when cells were harvested at 5 days (2).

Evaluation of potential for graft-vs.-host reactivity. Conceivably, passage of immunocompetent cells might provoke a graft-vs.-host (GVH) response in the W/L recipients (6). To assess this potential, experiments involving a popliteal lymph node weight assay in rats (7) were performed. 10- to 12 -wkold W/L rats received subcutaneous injections of $9 \times 10^{6} \mathrm{~W} / \mathrm{L}$ splenocytes suspended in $0.1 \mathrm{ml}$ sterile phosphate-buffered saline in the right volar hindpaw and the same volume of phosphate-buffered saline alone on the left. Total popliteal lymph node weight was then determined on both sides when the recipients were killed 7 days later. GVH reactivity would be expected to increase the weight of the responding nodes on the right (7).

Collagens. Native type I and II collagens were solubilized from lathyritic chick skin and sterna, respectively, and purified by methods previously described (1). Purity was confirmed by uronic acid assay, carboxymethylcellulose chromatography, and amino acid analvsis (1).

Sensitizations. Donor rats were injected intradermally with $0.5 \mathrm{mg}$ of type II collagen dissolved in $0.5 \mathrm{ml} 0.1 \mathrm{M}$ acetic acid at $4^{\circ} \mathrm{C}$ and emulsified in $0.5 \mathrm{ml}$ cold ICFA, as previously described (1). Control rats were sensitized in the same manner with an identical amount of type I collagen. Other control donors received intradermal injections of the acetic acid without collagen in ICFA. CFA was not employed in these experiments because this agent is capable of inducing an arthritis in rats on its own accord (1).

Antibody quantitation. Sera were tested for antibodies to type I or II collagen by passive microhemagglutination using human (group $\mathbf{O}, \mathbf{R h}+$ ) erythrocytes fixed by glutaraldehyde and sensitized with collagen, as we have previously described (2). Titers, after comparison to those of reference antisera and to sera from control rats not sensitized with collagen, were expressed as $-\log _{2}$ units.
Quantitation of cellular sensitivity to collagen. Cellular sensitivity to type II collagen was assayed by antigen-induced $\left[{ }^{3} \mathrm{H}\right] \mathrm{TdR}$ incorporation in vitro by blood mononuclear cells cultured in quadruplicate by a microtechnique which we have previously described (2). Like the MLC, all assays included phytohemagglutinin-stimulated cells as a control.

Cell transfers. Rats were sacrificed by ether anesthesia either 11-21 days after injection of type II collagen or after the onset of clinically recognizable arthritis (11-28 days postinjection). Control rats injected with type I collagen or ICFA alone were sacrificed at 11-21 days. Cells from uninjected rats of the same age provided an additional control. The spleen and cervical and inguinal lymph nodes were removed using sterile technique and placed in Hanks' balanced salt solution (HBSS, Microbiological Associates). The pooled spleen and lymph nodes were thoroughly teased, and cells were aspirated off, washed three times in HBSS, counted with a Coulter Counter (Coulter Electronics, Inc., Hialeah, Fla.), and tested for viability by exclusion of $0.2 \%$ trypan blue. Suspensions of 6-10 $\times 10^{8}$ cells in $1.5 \mathrm{ml}$ HBSS were then slowly injected into a tail vein of recipient rats.

As an antigen control, collagen was added to pools of cells from some rats injected with ICFA. To accomplish this, type II collagen was dissolved at a concentration of $1.0 \mathrm{mg} / \mathrm{ml}$ in $0.1 \mathrm{M}$ acetic acid at $4^{\circ} \mathrm{C}$ for $48 \mathrm{~h}$. The collagen was next dialyzed for $24 \mathrm{~h}$ at $4^{\circ} \mathrm{C}$ against $0.1 \mathrm{M}$ calcium acetate and then cold HBSS for the final $4 \mathrm{~h}$ before administration. $0.5 \mathrm{ml}$ of the collagen solution was then added to the cell suspension immediately before intravenous injection. Exclusion of trypan blue confirmed that cells remained viable after the addition of collagen. Heat-killed sensitized cells provided an additional antigen control. Falcon 3033 tubes (Falcon Plastics, Div. of BioQuest, Oxnard, Calif.) containing suspensions of $8 \times 10^{8}$ cells from arthritic rats injected with type II collagen were immersed in boiling water for $3 \mathrm{~min}$ immediately before intravenous injection. Although the cells remained intact, all cells were stained by trypan blue after this procedure.

Serum transfers. Blood was obtained by cardiac puncture from type II collagen-immunized donors that were arthritic at the time they were sacrificed. Sera were pooled and stored at $-70^{\circ} \mathrm{C}$. After thawing and determining antibody titers to type II collagen, $3.0-\mathrm{ml}$ aliquots were injected i.v. into recipient rats.

Clinical evaluation. Clinical examination for arthritis was conducted daily. Severity was quantified by a conventional arthritic index in which limbs were graded 0 to 4, representing increasing erythema and swelling and by measurement of the intermalleolar thickness of the ankle by the same observer with a constant tension caliper (B. C. Ames, Co., Waltham, Mass.). Both techniques were previously described (1). The reproducibility of the caliper measurements was determined by comparing readings performed in a blind fashion on 2 successive days. Analysis of 105 ankle measurements in normal age-matched W/L rats yielded an intermalleolar thickness of $6.4 \pm 0.1 \mathrm{~mm}$ (mean $\pm \mathrm{SEM}$ ) with an estimated intraobserver average error $(8)$ of $0.3 \mathrm{~mm}$ for two individual readings. Presence of arthritis in recipients was always confirmed by a blind technique utilizing different evaluators outside of the investigators' study group. This was done by mixing an arthritic rat with three nonarthritic rats before presentation to two independent evaluators, who were asked to identify any that had both redness and swelling of at least one hindlimb. Occasionally, observers were presented with four nonarthritic rats.

Histologic evaluation. Recipients of experimental and control cells were sacrificed 21 days after transfer, and their ankles were processed for histologic examinations, as previously described (1). Ankles of rats receiving arthritic sera were 
evaluated after sacrificing 10 days post-transfer. Cross sections of the ankle, stained with hematoxylin and eosin, were randomized and coded to allow examination by a blind technique for evidence of synovial inflammation by light microscopy. Presence of synovitis was independently confirmed in all recipients by a pathologist (Dr. John Caulfield).

Roentgenographic evaluation. Hindlimbs of recipients were evaluated radiographically for soft-tissue swelling and joint destruction by methods previously described (1).

Immunologic evaluation. Sera from all rats receiving cells or serum were tested for hemagglutinating antibodies to the appropriate collagen at the time of sacrifice. Recipients that became arthritic were tested for cellular sensitivity to type II collagen by $\left[{ }^{3} \mathrm{H}\right] \mathrm{TdR}$ incorporation studies using blood mononuclear cells obtained at sacrifice.

\section{RESULTS}

Histocompatibility of W/L rats and absence of GVH reactivity. Histocompatibility of these W/L rats was confirmed by skin graft acceptance and MLC testing. Although three of five attempted W/L full thickness skin grafts failed for technical reasons, grafts survived for greater than $3 \mathrm{mo}$ in the other two rats, indicating the syngeneic nature of this strain. MLC also documented the absence of major histocompatibility differences in these rats. Five MLC assays yielded a mean counts per minute $\pm \mathrm{SEM}$ of $420 \pm 63$ for the single $\mathrm{W} / \mathrm{L}$ cell cultures, $898 \pm 203$ for the two-way $\mathrm{W} / \mathrm{L} \times \mathrm{W} / \mathrm{L}$ cell cultures, $7686 \pm 890$ for the one-way W/L $\times$ Wistar stimulator-cell cultures, and 12,160 $\pm 2,064$ for the W/L cells cultured with phytohemagglutinin. Popliteal lymph node weight assays indicated that passage of lymphoid cells in W/L rats was unlikely to evoke a GVH response. In 10 rats, the mean total popliteal lymph node weight was $10.2 \pm 1.5 \mathrm{mg}$ for the experimental limb injected

TABLE I

Cell Transfer of Type II Collagen-Induced Arthritis

\begin{tabular}{lcc}
\hline \multicolumn{1}{c}{ Donor rats immunized with } & $\begin{array}{c}\text { Arthritis } \\
\text { present in } \\
\text { donors }\end{array}$ & $\begin{array}{c}\text { No. of rats } \\
\text { developing } \\
\text { arthritis/total } \\
\text { recipients }\end{array}$ \\
\hline Experimental & & \\
Chick type II collagen + ICFA & + & $4 / 10$ \\
& - & $5 / 22$ \\
Total & & $9 / 32$ \\
Control & & \\
Chick type II collagen + ICFA & $+*$ & $0 / 16$ \\
Chick type I collagen + ICFA & - & $0 / 24$ \\
ICFA & - & $0 / 20$ \\
ICFA alone & - & $0 / 20$ \\
Unimmunized & - & $0 / 17$ \\
Total & & $0 / 97$ \\
\hline
\end{tabular}

* Sensitized cells heat-killed before intravenous injection. \$ Solubilized type II collagen added to unsensitized cells at time of intravenous injection. with W/L cells vs. $10.1 \pm 2.1 \mathrm{mg}$ for the control limb injected with phosphate-buffered saline.

Cell transfer of arthritis. Table I shows the results of our cell transfer studies for both experimental and control groups. 9 of $32(28 \%)$ rats receiving cells from donors injected with type II collagen developed clinically apparent arthritis. If only those rats receiving cells from pools at least partially comprised of arthritic donors are considered, 4 of 10 transfers resulted in arthritis. All nine arthritic rats were correctly identified by the observers outside of the investigators' study group. No rats were erroneously adjudged to be arthritic by these evaluators. In contrast, Table I also indicates that arthritis failed to develop in control groups employing a total of 97 recipients. Thus, the incidence of arthritis in the experimental group was highly significant $(P<0.0001$ by chi-square analysis) when compared to the absence of arthritis in the control group.

Controls examined included recipients of cells from unimmunized donors, recipients of cells from donors injected with ICFA alone, recipients of cells from donors injected with type I collagen in ICFA, recipients of cells from ICFA-injected donors to which solu-

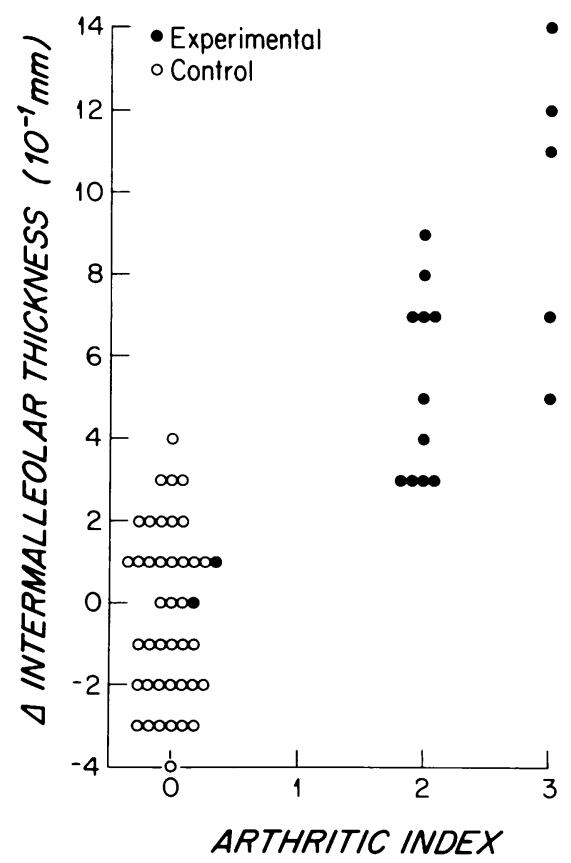

FIGURE 1 Quantitation of hindlimb involvement by arthritis in cell recipients by caliper measurement and arthritic index. Change in intermalleolar thickness represents difference in two successive caliper readings performed by blind technique on separate days. (-) Caliper values and concurrent index of the 18 ankles from the recipients of cells sensitized to type II collagen at the onset of clinical arthritis. $(O)$ Values recorded for a control group, consisting of 40 hindlimbs of the agematched rats that received unsensitized cells to which type II collagen had been added. 
bilized type II collagen had been added at the time of transfer, and recipients of heat-killed cells from rats with type II collagen-induced arthritis. The failure of the latter two groups to become arthritic shows that the successful transfer of disease was not due simply to passage of antigen.

Evaluation of arthritis. The arthritis induced in recipients by cells sensitized to type II collagen was less severe than its counterpart in donors. Arthritis was first apparent $5-10$ days (mean $6.7 \pm 0.7$ ) after cell transfer. Ordinarily, rats received a pool of $6-10 \times 10^{8}$ spleen and lymph node cells; however, one rat developed arthritis after injection of only $4 \times 10^{8}$ cells. Intravenous administration of cells appeared to be of critical importance because intraperitoneal injection of 20 rats with 1-2 $\times 10^{9}$ cells from type II collagen-injected donors failed to induce arthritis.

The ankle was the most frequently affected joint, and both hindlimbs were involved in seven of the nine arthritic recipients. Although compression of the swollen ankles by the constant tension caliper minimized the changes recorded by this technique, increases in the intermalleolar thickness of $0.3-1.4 \mathrm{~mm}$ were detected at the onset of arthritic involvement. This repre- sents up to a $22 \%$ increase in the total thickness of the ankle and is above the estimated average error for our caliper measurements of $0.3 \mathrm{~mm}$ (Fig. 1). Limbs were also graded 0 to 4 by a conventional arthritic index. Involved limbs in arthritic donors were consistently scored 4 at the time of sacrifice (Fig. 2). Disease transferred by cells displayed milder features with a mean score of $2.3 \pm 0.2$ for the 16 involved limbs (Fig. $3)$. All joints in the recipients that were considered arthritic had an index of 2 or 3.

Inflammation persisted for at least $2 \mathrm{wk}$ (Fig. 4). All joints from the arthritic recipients were evaluated histologically at sacrifice approximately $2 \mathrm{wk}$ after the onset of disease and showed active synovitis, consisting of hyperplasia of the synoviocytes and infiltration by numerous mononuclear cells (Fig. 5). Only minimal bone and cartilage destruction was found. Joint radiographs performed in six of the nine arthritic recipients at sacrifice showed soft-tissue swelling of the hindlimbs but no bone erosion or periostitis.

Evaluation of arthritic recipients for humoral and cellular sensitivity to type II collagen. Evidence of humoral and cellular responses to type II collagen differed in arthritic donors and recipients. In contrast to

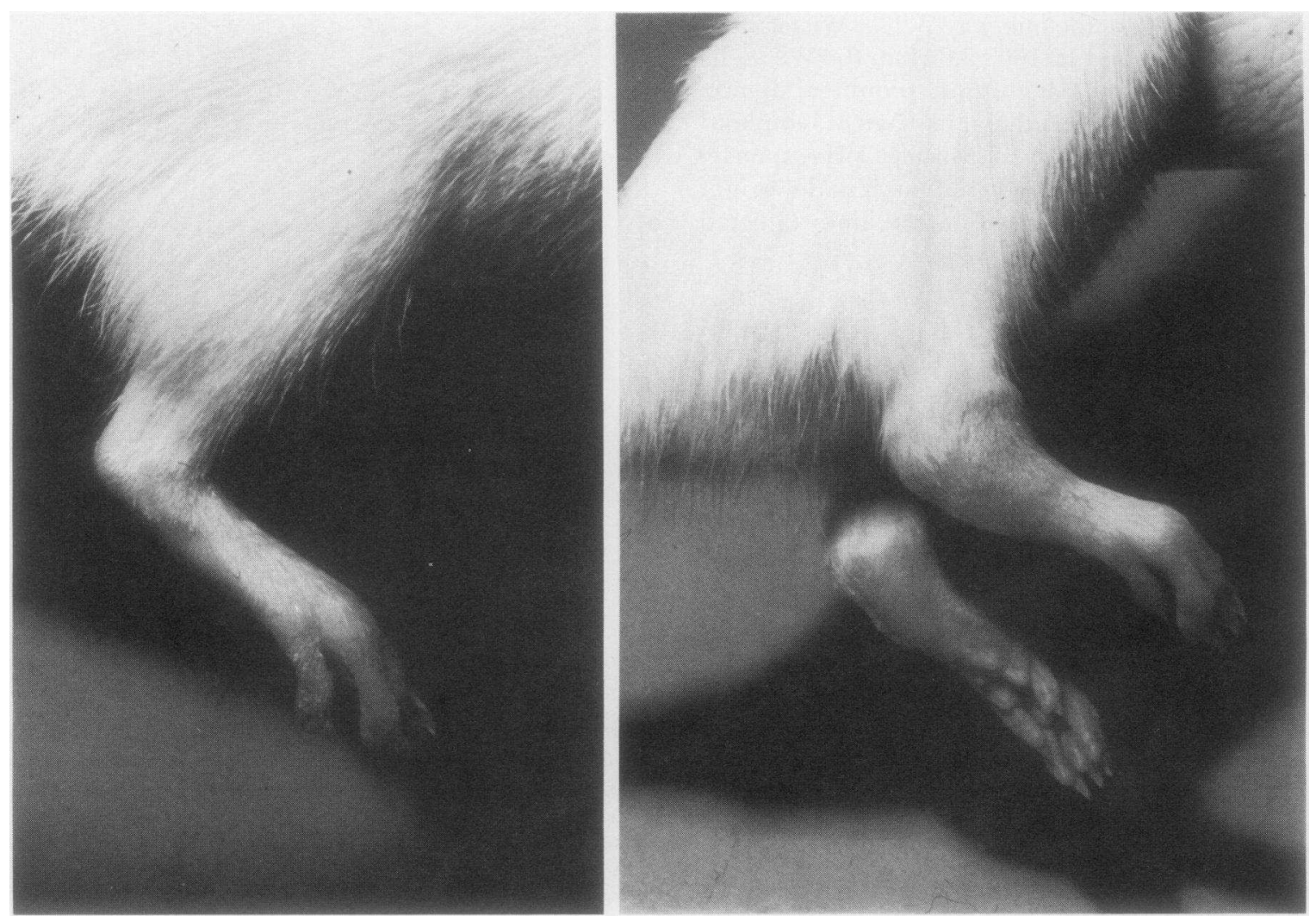

FIGURE 2 Ankle of arthritic donor rat on the right scored 4 by the arthritic index compared with a normal rat on the left. 

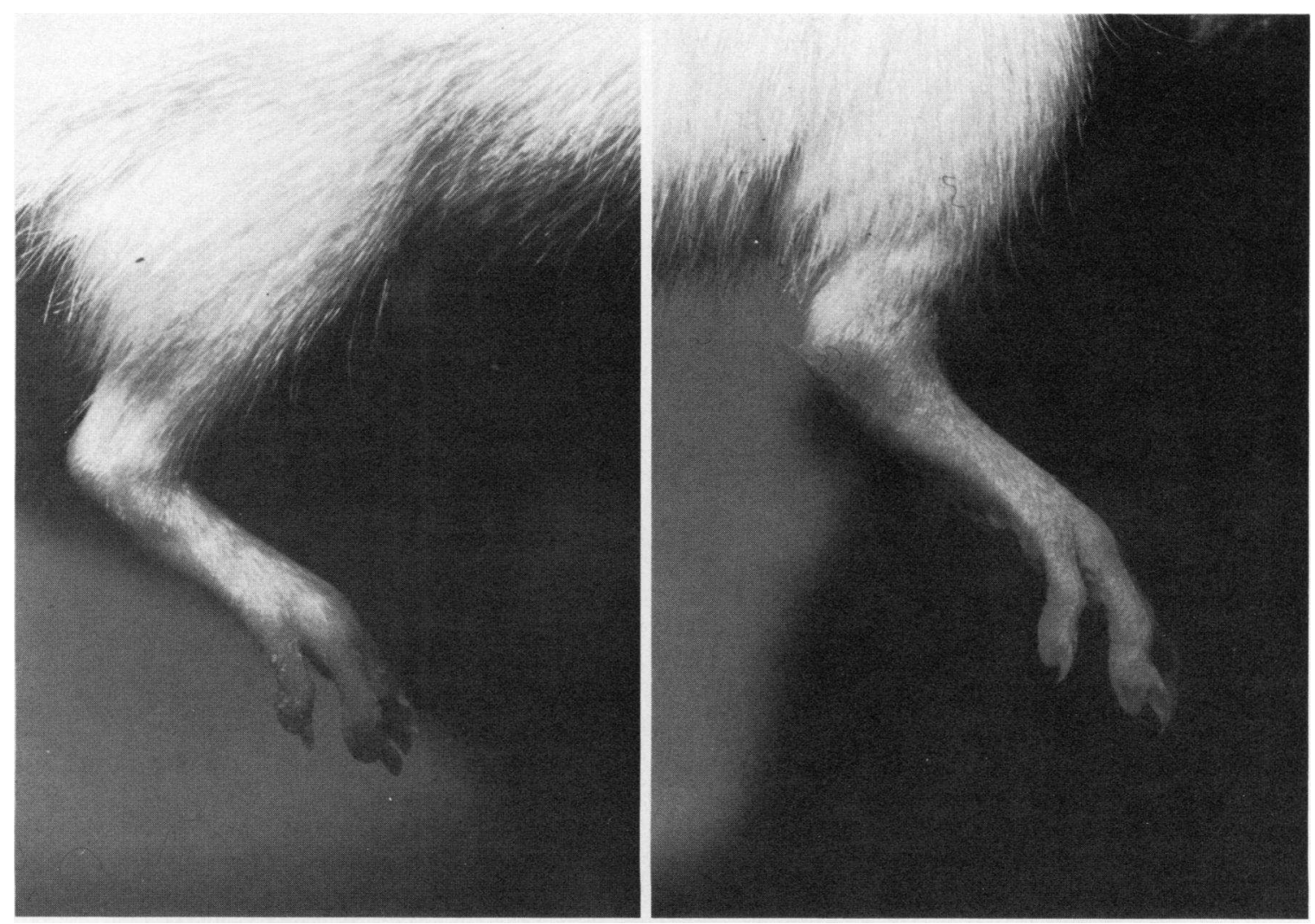

FIGURE 3 Arthritic ankle of recipient of cells sensitized to type II collagen on the right compared with a normal ankle on the left. This ankle was scored 2 by the arthritic index.

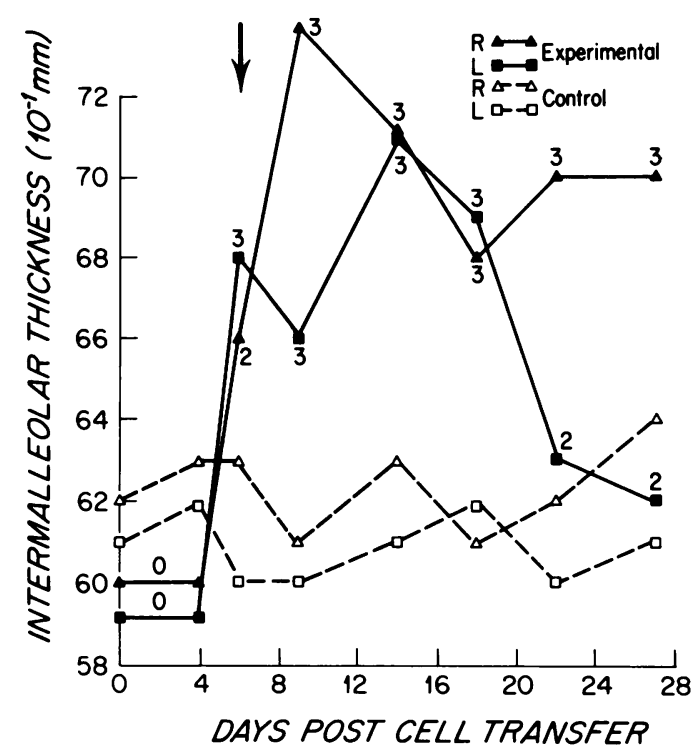

FIgUre 4 Course of bilateral ankle swelling assessed by caliper measurements and arthritic index in an arthritic recipient of cells sensitized to type II collagen compared with values for a control rat receiving type II collagen and unsensitized cells. Measurements were performed by the same ob- the high antibody titers to type II collagen uniformly observed in rats injected with this collagen (2), sera from all 32 rats receiving cells from type II collageninjected donors did not contain hemagglutinating antibodies to this collagen when tested 3 wk after cell transfer. Also contrasting with the cellular sensitivity to collagen regularly demonstrated in rats rendered arthritic by injection of type II collagen (2), blood mononuclear cells from rats whose arthritis had been induced by sensitized cells did not exhibit enhanced $\left[{ }^{3} \mathrm{H}\right] \mathrm{TdR}$ incorporation to this protein.

Evaluation of controls. Clinical and histologic evaluation and caliper measurements documented the absence of arthritis in the 97 rats receiving control cells. No control showed a consistent increase in intermalleolar thickness or any appearance of joint inflammation.

server without knowledge of previous values on the days indicated after receipt of cells. Arthritis was first apparent in the experimental recipient (arrow) on day 6 and was bilateral at that time. Numbers adjacent to experimental caliper measurements represent arthritic index. All appraisals of the control rat merited an index score of 0 . It is apparent that arthritis persisted for $3 \mathrm{wk}$ until sacrifice in the recipient of sensitized cells. 


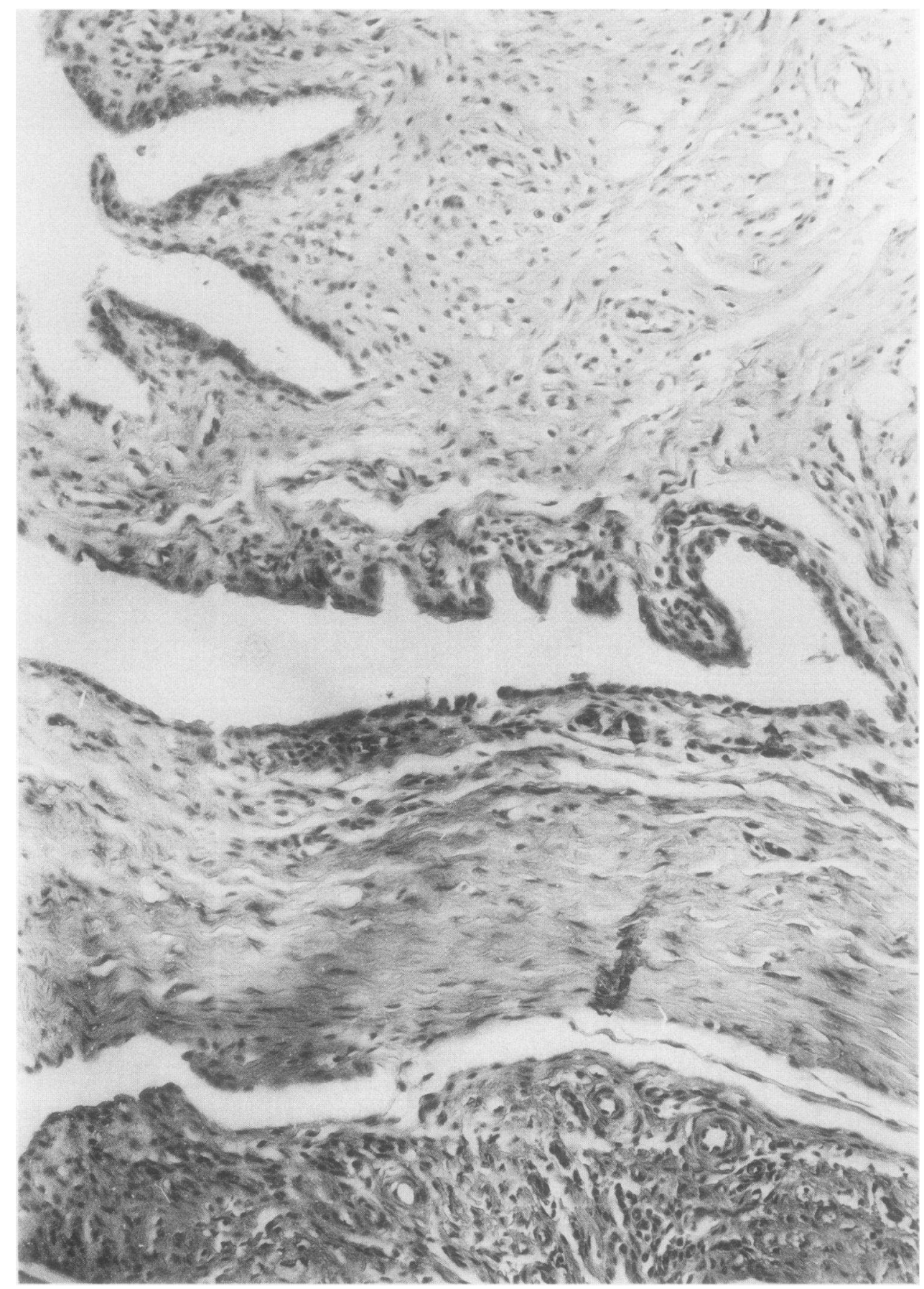

FIGURE 5 Histologic evidence of synovitis, consisting of synovial hyperplasia and mononuclear cell infiltration in arthritic ankle joint of rat that received cells sensitized to type II collagen 21 days earlier. Hematoxylin and eosin. $\times 200$. Photograph courtesy of Dr. John Caulfield.

Histologic evidence of ankle synovitis at the time of sacrifice was also lacking in the $\mathbf{5 0}$ controls examined bilaterally without knowledge of what type of cells, antigen, or serum the rat had received. There was no sign either clinically or histologically in sections of the skin and liver of GVH disease (6) in 10 control recipients so examined. Finally, none of the 24 rats receiving cells from donors injected with type I collagen or the 36 receiving the mixture of type II collagen and nonsensitized cells or heat-killed sensitized cells 
had circulating antibodies to type I or II collagen, respectively.

Serum transfer experiments. 30 rats receiving serum pooled from arthritic donors $\left(-\log _{2}\right.$ antibody titer 12 to type II collagen) failed to develop clinical or histologic evidence of arthritis. All had antibodies to type II collagen in their sera 10 days after transfer (mean titer 5.7 \pm 0.6 ).

\section{DISCUSSION}

Biochemically distinct types of collagens are distributed throughout various tissues. Type I collagen is found in skin, bone, tendon, and the parenchyma of many organs. Type II collagen appears to be localized to cartilage and the vitreous, retina (9), and cornea (10) of the eye. We have recently shown (1) that native collagen extracted from cartilage is arthritogenic for rats. Inasmuch as this collagen has the chromatographic characteristics and amino acid composition previously described for type II collagen (11), we assume that type II collagen is the arthritogenic moiety in our preparations. Both type I and II collagens can induce typespecific humoral (12) and cellular (2) sensitivities in rats. Thus, an immunologic response specific for type II collagen could explain the unique arthritogenicity of this cartilage collagen. Passive transfer by sensitized spleen and lymph node cells of type II collagen-induced arthritis provides direct support for this hypothesis.

Although these studies demonstrate that collageninduced arthritis can be passively transferred, they do not identify the type(s) of cells involved. Specifically, these experiments do not establish that the arthritic process is the result of cell-mediated immunologic mechanisms, because immunoglobulin-producing cells could have been transferred and subsequently induced synovitis. Although arthritic sera did not induce arthritis in these experiments, this does not exclude the possibility that B cells participate in disease causation. Full manifestations of this autoimmune disease may require an interaction of various subpopulations of mononuclear cells. This would be analogous to experimental allergic orchitis, where, although there appears to be an obligatory $\mathrm{T}$-cell requirement for disease induction (13), antibodies may be capable of potentiating inflammation (14). Transfer experiments involving $\mathrm{T}$ or B-cell-depleted populations, sensitized cells suspended in arthritic serum, and large quantities of antibodies to type II collagen are in progress. These studies may further characterize the cells responsible for this arthritis.

It was of interest that although the $\mathrm{W} / \mathrm{L}$ rats used in these experiments were demonstrated to be histocompatible, on the basis of skin graft survival and MLC testing, clinically apparent arthritis could be induced in only $\cong 40 \%$ of these rats by either primary injection of type II collagen (1) or transfer of cells from arthritic donors. The explanation for this is presently unknown but worth pursuing.

In these experiments, cells from both arthritic and clinically disease-free donors were capable of passively transferring arthritis. Our data might be interpreted to indicate that the development of arthritis in the donor was not a requisite for successful cell transfer of the disease. However, we would caution that cells from nonarthritic donors were obtained 11-21 days after injection of collagen. Because clinically apparent arthritis in the primary disease occasionally did not begin until the 4th wk after injection, it is likely that these transfers included cells from prearthritic donors; this could explain the successful induction of arthritis by cells from disease-free donors. It is also probable that sensitized cells from arthritic donors were diluted by pooling with cells from disease-free donors in some experiments. This might partially account for the low incidence of successful transfer of arthritis.

In conclusion, type II collagen-induced arthritis can be passively transferred by sensitized spleen and lymph node cells. This implies that immunologic hypersensitivity to the cartilage type of collagen initiates this autoimmune disease. Additional studies, however, are required to determine the precise role of $T$ and $B$ cells in the pathogenesis of the proliferative synovitis present in this animal model.

\section{ACKNOWLEDGMENTS}

We thank Dr. John Caulfield for histologic evaluation of synovia, Ms. Donna Rowland for excellent technical assistance, and Ms. Lynn Elam-Jones for manuscript preparation.

This work was supported by U. S. Public Health Service grants AI-07685 and AM-05076 and a grant from the New England Peabody Home Foundation.

\section{REFERENCES}

1. Trentham, D. E., A. S. Townes, and A. H. Kang. 1977. Autoimmunity to type II collagen: an experimental model of arthritis. J. Exp. Med. 146: 857-868.

2. Trentham, D. E., A. S. Townes, A. H. Kang, and J. R. David. 1978. Humoral and cellular sensitivity to collagen in type II collagen-induced arthritis in rats. J. Clin. Invest. 61: 89-96.

3. Rose, N. R. 1973. Self-recognition and autoimmunity. In Principles of Immunology. N. R. Rose, F. Milgrom, and C. J. van Oss, editors. Macmillan Company, New York. 217-228.

4. Billingham, R. E. 1961. Free skin grafting in mammals. In Transplantation of Tissues and Cells. R. E. Billingham and W. K. Silvers, editors. The Wistar Institute Press, Philadelphia. 1-29.

5. Wilson, D. B. 1967. Quantitative studies on the mixed lymphocyte interaction in rats. I. Conditions and parameters of response. J. Exp. Med. 126: 625-654.

6. Billingham, R. E., V. Defendi, W. K. Silvers, and D. Steinmuller. 1962. Quantitative studies on the induction of 
tolerance of skin homografts and on runt disease in neonatal rats. J. Natl. Cancer Inst. 28: 365-436.

7. Ford, W. L., W. Burr, and M. Simonsen. 1970. A lymph node weight assay for the graft-versus-host activity of rat lymphoid cells. Transplantation (Baltimore). 10: 258266.

8. Lutz, W. 1973. Statistical methods as applied to immunological data. In Handbook of Experimental Immunology. Vol. 3. D. M. Weir, editor. Blackwell Scientific Publications Ltd., Oxford. 2nd edition. Al.11.

9. Smith, G. N., Jr., T. F. Linsenmayer, and D. A. Newsome. 1976. Synthesis of type II collagen in vitro by embryonic chick neural retina tissue. Proc. Natl. Acad. Sci. U. S. A. 73: 4420-4423.

10. Linsenmayer, T. F., G. N. Smith, Jr., and E. D. Hay. 1977. Synthesis of two collagen types by embryonic chick corneal epithelium in vitro. Proc. Natl. Acad. Sci. U. S. A. 74: $39-43$.

11. Miller, E. J. 1971. Isolation and characterization of a collagen from chick cartilage containing three identical $\alpha$-chains. Biochemistry. 10: 1652-1659.

12. Hahn, E., R. Timpl, and E. J. Miller. 1974. The production of specific antibodies to native collagens with the chain compositions, $[\alpha \mathrm{l}(\mathrm{I})]_{3},[\alpha \mathrm{l}(\mathrm{II})]_{3}$, and $[\alpha \mathrm{l}(\mathrm{I})]_{2} \alpha 2 . \mathrm{J}$. Immunol. 13: 421-423.

13. Tung, K. S. K., C. Leong, and T. McCarty. 1977. Pathogenesis of experimental allergic orchitis. III. T lymphocyte requirement in local adoptive transfer by peritoneal exudate cells. J. Immunol. 118: 1774-1779.

14. Tung, K. S. K., E. R. Unanue, and F. J. Dixon. 1971. Pathogenesis of experimental allergic orchitis. II. The role of antibody. J. Immunol. 106: 1463-1472. 